\title{
Optical and Electrical Properties of (002)-Oriented ZnO Films Prepared on Amorphous Substrates by Sol-Gel Spin-Coating
}

\author{
Gonzalo Alonso Velázquez-Nevárez $z^{a *,}$,Jorge Roberto Vargas-García ${ }^{a}$, Jorge Aguilar-Hernández ${ }^{b}$, \\ Oscar Edgardo Vega-Becerrac, Fei Chen ${ }^{d}$, Qiang Shen ${ }^{d}$, Lianmeng Zhang ${ }^{d}$
}

\author{
${ }^{a}$ Depto. Ing. Metalurgia y Materiales, Escuela Superior de Ingeniería Química e Industrias Extractivas \\ - ESIQIE, Instituto Politécnico Nacional - IPN, Ciudad de México, 07738, DF, México \\ ${ }^{b}$ Escuela Superior de Física y Matemáticas, Instituto Politécnico Nacional - IPN, Edificio No. 9, \\ UPALM, Ciudad de México, 07738, DF, México \\ ${ }^{c}$ Research Center of Advanced Materials - CIMAV, Apodaca, 66600, Nuevo León, México \\ ${ }^{d}$ State Key Laboratory of Advanced Technology for Materials Synthesis and Processing, Wuhan \\ University of Technology, Wuhan, 430070, Hubei Province, China
}

Received: October 29, 2016; Accepted: November 23, 2016

\begin{abstract}
Zinc oxide $(\mathrm{ZnO})$ films were prepared on amorphous quartz substrates by sol-gel spin-coating using $\mathrm{Zn}\left(\mathrm{CH}_{3} \mathrm{COO}\right)_{2} \cdot 2 \mathrm{H}_{2} \mathrm{O}$ precursor. Isopropanol, ethanol and 2-methoxyethanol were used as solvents. The film drying temperature was kept constant at $200{ }^{\circ} \mathrm{C}$ and the annealing temperature was varied from 400 to $800^{\circ} \mathrm{C}$. Highly transparent and (002)-oriented hexagonal wurtzite-type $\mathrm{ZnO}$ films were obtained using isopropanol solvent. The $\mathrm{ZnO}$ films prepared at $\mathrm{T}_{\text {anneal }}=600{ }^{\circ} \mathrm{C}$ showed the highest (002) preferential orientation, however it was not the significant feature to achieve low resistivity. The uniform and (002)-oriented $\mathrm{ZnO}$ films prepared at $\mathrm{T}_{\text {anneal }}=400{ }^{\circ} \mathrm{C}$ display the highest transmittance ( $>93 \%$ in the visible region) and the lowest resistivity $(7.1 \Omega \bullet \mathrm{cm})$.
\end{abstract}

Keywords: Zinc oxide films, Oriented films, Transparent and conductive films

\section{Introduction}

Cost-effective transparent conductive oxide (TCO) films are increasingly demanded for a number of electronic devices such as solar cells, flat panel displays and light-emitting diodes $^{1}$. So far, tin-doped indium oxide (ITO) is the most common TCO owing to its superior electrical conductivity and optical transmission. However, the success of ITO is limited by the high cost, toxicity and scarcity of indium ${ }^{2-4}$. In search of alternative materials, $\mathrm{ZnO}$ has attracted much attention because of its relatively low cost, wide band gap of $3.37 \mathrm{eV}$, large exciton binding energy $(60 \mathrm{meV})$ and distinctive surface effect (1.53 eV surface band bending) 5 . Thus, $\mathrm{ZnO}$ thin films have been prepared by a large number of techniques such as chemical bath deposition ${ }^{6}$, sputtering ${ }^{7}$, SILAR $^{8}$, spray pyrolysis ${ }^{9}$, chemical vapor deposition $(C V D)^{10}$ and sol-gel ${ }^{11}$. Among these, sol-gel spin-coating has received increasing attention because it is a simple and cost-effective process for the preparation of uniform oxide films with adequate control of their morphology, structure and stoichiometry ${ }^{12}$. The electrical conductivity and optical properties of $\mathrm{ZnO}$ thin films have been associated with the increase of (002)-orientation degree of its hexagonalwurtzite crystal structure ${ }^{2,13-14}$. Transparent and conductive (002)-oriented $\mathrm{ZnO}$ films have been prepared by sol-gel spin-coating, however, the use of single crystal substrates and doping elements have been required ${ }^{15-17}$. In addition,

* e-mail: gvelazquezn1300@alumno.ipn.mx undoped and (002)-oriented $\mathrm{ZnO}$ films grown on amorphous substrates by sol-gel have also been reported to show relatively attractive electrical and optical properties ${ }^{18,19}$. In this study, it is shown that the (002)-orientation is not the significant feature to achieve low resistivity in $\mathrm{ZnO}$ films prepared by sol-gel spin-coating on amorphous substrates.

\section{Experimental}

Zinc oxide precursor solutions were prepared from zinc acetate dihydrate $\left(\mathrm{Zn}\left(\mathrm{CH}_{3} \mathrm{COO}\right)_{2} \cdot 2 \mathrm{H}_{2} \mathrm{O}\right.$, Sigma-Aldrich, purity $\geq 98 \%)$ as metal source, monoethanolamine $\left(\mathrm{C}_{2} \mathrm{H}_{7} \mathrm{NO}\right.$, Sgima-Aldrich, purity $\geq 99.0 \%$ ) as a stabilizer, and three different alcohols; isopropanol $\left(\mathrm{C}_{3} \mathrm{H}_{8} \mathrm{O}\right.$, Sigma-Aldrich, purity 99.5\% ), 2-methoxyethanol $\left(\mathrm{C}_{3} \mathrm{H}_{8} \mathrm{O}_{2}\right.$, Sigma-Aldrich, purity $\geq 99.5 \%)$, and ethanol $\left(\mathrm{C}_{2} \mathrm{H}_{6} \mathrm{O}\right.$, Reactivos Analíticos, purity $99.7 \%$ ), as solvents. First, the stabilizer agent and separately individual solvent were mixed by magnetic stirring at 50 ${ }^{\circ} \mathrm{C}$ for $10 \mathrm{~min}$. Then, the metal precursor was dissolved in the previous mixture at $60{ }^{\circ} \mathrm{C}$ for $2 \mathrm{~h}$ to obtain $0.5 \mathrm{~mol} \cdot \mathrm{L}^{-1}$ $\mathrm{Zn}\left(\mathrm{CH}_{3} \mathrm{COO}\right)_{2} \cdot 2 \mathrm{H}_{2} \mathrm{O}$ solutions. The stabilizer to metal source molar ratio was kept constant at $1\left(\mathrm{R}_{\mathrm{MEA}}=1\right)$. Regardless of solvent, the resultant solutions were clear without any precipitates. The resultant solutions were aged for $24 \mathrm{~h}$ at room temperature before the film preparation. $\mathrm{ZnO}$ films were prepared on quartz substrates $25 \mathrm{~mm} \times 25 \mathrm{~mm} \times 1 \mathrm{~mm}$ in size. Previous to film preparation, the quartz substrates were 
sequentially cleaned with acetone, ethanol and deionized water by using ultrasonic bath. Then, the substrates were blown dried using dry air. Appropriate spin-coating parameters to prepare the films were as follows: $300 \mathrm{rpm}$ for $5 \mathrm{~s}$ and then $3000 \mathrm{rpm}$ for $30 \mathrm{~s}$. Films thus prepared were dried at 200 ${ }^{\circ} \mathrm{C}$ for $10 \mathrm{~min}$ in air by using a horizontal-tubular furnace. Multi-layers films were prepared by sequentially repeating the spin-coating and drying steps for 5 times. Annealing treatment of multi-layer films was performed from 400 to $800{ }^{\circ} \mathrm{C}$ for $2 \mathrm{~h}$ in air. The heating rate was kept at $10^{\circ} \mathrm{C} / \mathrm{min}$. The film surface morphology was examined by using a field emission scanning electron microscope (FESEM; JEOL JSM-6071F). The crystalline structure of films was investigated by X-ray diffraction (XRD; BRUKER D8 Advanced) coupled with grazing geometry using an incident $\mathrm{X}$-ray beam from $0.5^{\circ}$ to $3.0^{\circ}$. For transmission electron microscopy (TEM; JEOL JEM ARM 200CF) observations, the films were removed from the quartz substrate and then, the collected flakes were dispersed in isopropanol using an ultrasonic bath. A sample of the suspension was then taken and deposited on $\mathrm{Cu}$ grid (Tedpella). The optical transmittance of films was measured by UV-vis spectroscopy (Perkin Elmer Lambda 35) in the wavelength range of $200-800 \mathrm{~nm}$ at room temperature. Photoluminescence, PL characteristics, at room temperature, were measured employing a He:Cd laser $(\lambda=325 \mathrm{~nm})$ as excitation source, a double monochromator (1403-SPEX) and a photomultiplier detector (RCA-C310334). The uncoated quartz substrate was used as a blank reference for base line determination. The sheet resistance, $R$ of films was measured by the four-point method at room temperature on three different locations for every sample using a KEITHLEY 2601A source/meter instrument. The film resistivity was calculated from $\rho=\mathrm{R} \times \mathrm{t}$, where " $\mathrm{t}$ " is the film thickness and " $R$ " is the sheet resistance.

\section{Results and discussion}

Figure 1 (a) shows the effect of solvent type on the XRD patterns of $\mathrm{ZnO}$ films prepared at $\mathrm{T}_{\text {anneal }}=600^{\circ} \mathrm{C}$. All films are polycrystalline in nature with well-defined diffraction peaks corresponding to the (100), (002), (101), (102), (110), (103), (112) and (201) planes of the hexagonal wurtzite-type crystal structure of $\mathrm{ZnO}$ (JCPDS card 36-1451) ${ }^{12}$. In particular, the $\mathrm{ZnO}$ films prepared with isopropanol and ethanol solvents exhibit high intensity of the (002) diffraction peak as demanded for optoelectronic film applications ${ }^{1,2}$. Isopropanol and ethanol are preferred as solvents in materials processing because of their less toxic nature for human and environment than 2-methoxyetanol ${ }^{20}$. Figure 1 (b) shows the effect of annealing temperature on the XRD patterns of $\mathrm{ZnO}$ films prepared with isopropanol. As annealing temperature increases from 400 to $600{ }^{\circ} \mathrm{C}$, a remarkable high (002) diffraction intensity is observed indicating $c$-oriented $\mathrm{ZnO}$ films.
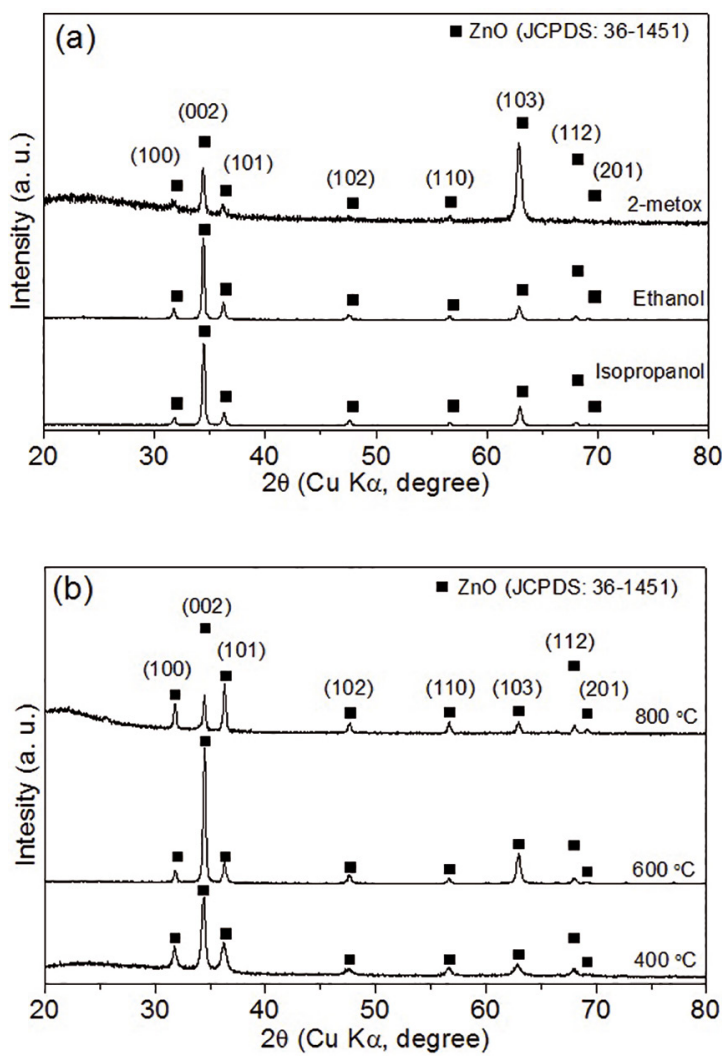

Figure 1: (a) Effect of solvent type on the XRD patterns of $\mathrm{ZnO}$ films prepared at $\mathrm{T}_{\text {anneal }}=600^{\circ} \mathrm{C}$ (b) Effect of annealing temperature on the $\mathrm{XRD}$ patterns of $\mathrm{ZnO}$ films prepared with isopropanol.

The (002) preferential orientation of $\mathrm{ZnO}$ films was determined by using the Lotgering Factor $L F$ as follows ${ }^{21}$ :

$$
L F=\frac{P-P_{0}}{1-P_{0}}
$$

where $\mathrm{P}=\mathrm{I}_{(002)} / \Sigma \mathrm{I}_{(h k l)}$, and $\mathrm{P}_{0}=\mathrm{I}_{0(002)} / \Sigma \mathrm{I}_{0(h k l)}$. I and $\mathrm{I}_{0}$ are diffraction intensities of oriented and randomly oriented films, respectively. $\Sigma \mathrm{I}_{(h k l)}$ and $\Sigma \mathrm{I}_{0(h k l)}$ are the sum of all diffraction peak $(h k l)$ intensities in the range of $20^{\circ}<2 \theta<80^{\circ}$. The $L F$ varies between zero to unity; $L F=0$ corresponds to random orientation, and $L F=1$ to perfect orientation. Figure 2 shows the $L F$ values for the (002) diffraction peak of $\mathrm{ZnO}$ films prepared with isopropanol and 2-methoxyethanol as a function of annealing temperature. Below $\mathrm{T}_{\text {anneal }}=600^{\circ} \mathrm{C}, \mathrm{ZnO}$ films prepared with isopropanol exhibit higher $L F$ values compared to those obtained with 2-methoxyethanol. Particularly, $\mathrm{ZnO}$ films prepared with isopropanol exhibit the highest $L F$ of 0.57 at $\mathrm{T}_{\text {anneal }}=600{ }^{\circ} \mathrm{C}$. At higher temperatures, however, $\mathrm{ZnO}$ films show less degree of (002) preferential orientation.

Calculated values of lattice parameters and crystal size are summarized in Table 1. The lattice parameters $a$ and $c$ of the hexagonal structure were calculated by the following formula ${ }^{22}$ : 


$$
d_{h k l^{2}}=\left[\frac{4\left(h^{2}+k^{2}+h k\right)}{3 a^{2}}+\frac{l^{2}}{c^{2}}\right]^{-1}
$$

where $d$ is the interplanar distance and $h, k$, $l$ are the Miller indices. The calculated lattice parameters are very close to those reported in the JCPDS card 36-1451 $(a=3.2498 \AA$, $c=5.2066 \AA$ ).

The mean crystal size was calculated by Scherrer's formula ${ }^{23}$ :

$$
D=\frac{0.9 \lambda}{\beta \cos \theta}
$$

where $D$ is the crystal size, $\beta$ the full-width at half maximum of a distinctive peak (rad), $\theta$ the Bragg angle and $\lambda=1.5405 \AA(\mathrm{Cu} \mathrm{K} \alpha)$. As indicated in Table 1, the crystal size increases with the annealing temperature.

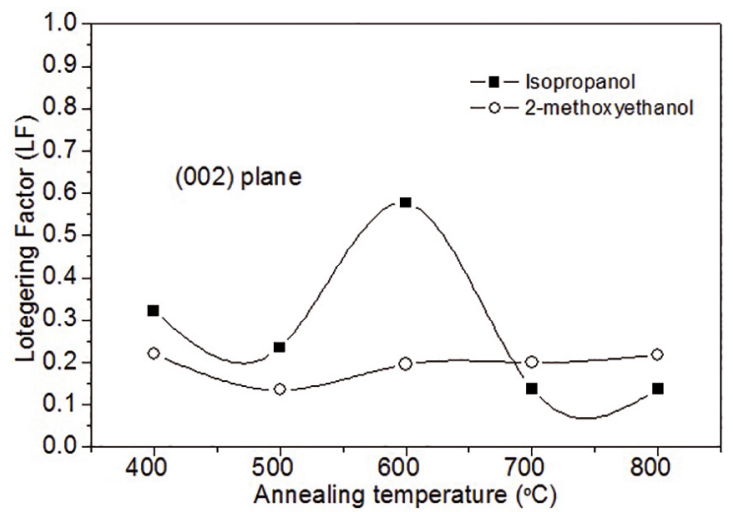

Figure 2: $L F$ values for the (002) diffraction peak of $\mathrm{ZnO}$ films prepared with isopropanol and 2-methoxyethanol as function of annealing temperature.

Table 1: Lattice parameters and crystal size of $\mathrm{ZnO}$ films prepared at $\mathrm{T}_{\text {anneal }}=400,600$ and $800{ }^{\circ} \mathrm{C}$.

\begin{tabular}{lccc}
\multicolumn{4}{c}{ Lattice parameters } \\
$\mathrm{T}_{\text {anneal }}\left({ }^{\circ} \mathrm{C}\right)$ & $a$-lattice $(\AA)$ & $c$-lattice $(\AA)$ & $\mathrm{D}_{(002)}(\mathrm{nm})$ \\
\hline 400 & 3.2498 & 5.2113 & 20.4 \\
600 & 3.2430 & 5.1998 & 27.4 \\
800 & 3.2452 & 5.1993 & 27.9 \\
\hline
\end{tabular}

Figure 3 shows TEM images at different amplifications of scratched sample taken from $\mathrm{ZnO}$ films prepared at $\mathrm{T}_{\text {anneal }}=$ $400{ }^{\circ} \mathrm{C}$. Figure 3 (a) reveals that $\mathrm{ZnO}$ films consist of equiaxial grains of around $20 \mathrm{~nm}$, which is consistent with the crystal size calculated from the Scherrer's formula. High-resolution observations indicate an interplanar distance of $0.26 \mathrm{~nm}$, in agreement with the (002) plane of $\mathrm{ZnO}$ hexagonal structure.

Figure 4 shows SEM images of the surface morphology and cross-section of $\mathrm{ZnO}$ films prepared with isopropanol at (a)-(d) $\mathrm{T}_{\text {anneal }}=400{ }^{\circ} \mathrm{C}$, (b)-(e) $\mathrm{T}_{\text {anneal }}=600^{\circ} \mathrm{C}$ and (c)-(f) $\mathrm{T}_{\text {anneal }}=800^{\circ} \mathrm{C}$. Films exhibit a granular surface morphology
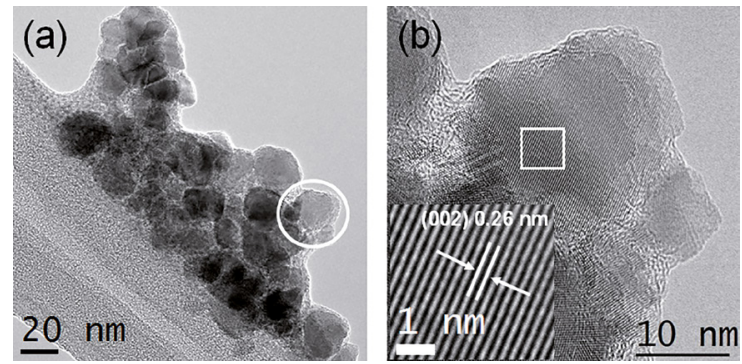

Figure 3: TEM images at different amplifications of scratched sample taken from $\mathrm{ZnO}$ films prepared at $\mathrm{T}$ $=400{ }^{\circ} \mathrm{C}$.
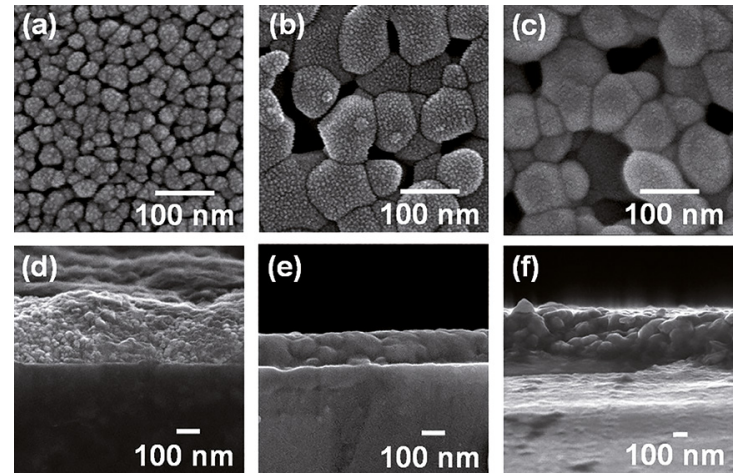

Figure 4: SEM images of the surface morphology and cross-section of $\mathrm{ZnO}$ films prepared with isopropanol at (a)-(d) $\mathrm{T}_{\text {anneal }}=400^{\circ} \mathrm{C}$, (b)-(e) $\mathrm{T}_{\text {anneal }}=600{ }^{\circ} \mathrm{C}$ and (c)-(f) $\mathrm{T}_{\text {anneal }}=800{ }^{\circ} \mathrm{C}$.

with a grain size notoriously increased from $\mathrm{T}_{\text {anneal }}=600^{\circ} \mathrm{C}$. From cross-section observations, the film thickness was found to be 280,140 and $320 \mathrm{~nm}$ for $\mathrm{ZnO}$ films prepared at $\mathrm{T}_{\text {anneal }}=400,600$ and $800{ }^{\circ} \mathrm{C}$, respectively. The relatively thick films obtained at $\mathrm{T}_{\text {anneal }}=800^{\circ} \mathrm{C}$ could be related with a remarkable porous morphology suggested from the surface images. As indicated by XRD results, the $140 \mathrm{~nm}$-thick $\mathrm{ZnO}$ films showed the highest (002) preferential orientation.

Figure 5 shows the UV-vis transmittance spectra for $\mathrm{ZnO}$ films prepared with isopropanol as a function of annealing temperature. All films exhibited transmittance above $85 \%$ in the visible region and a sharp fundamental absorption edge, as it has been previously observed ${ }^{24}$. In particular, $\mathrm{ZnO}$ films obtained at $\mathrm{T}_{\text {anneal }}=400{ }^{\circ} \mathrm{C}$ display the highest transmittance (>93\%) in the visible region. At $\mathrm{T}_{\text {anneal }}=600$ and $800{ }^{\circ} \mathrm{C}$, however, the optical transmittance decreases, which could be attributed to the contribution of larger grain size (see Table 1).

Figure 6 depicts the room-temperature photoluminescence spectra of $\mathrm{ZnO}$ films prepared at $\mathrm{T}_{\text {anneal }}=400,600$ and 800 ${ }^{\circ} \mathrm{C}$. Two photoluminescence emission bands are evident in these spectra. One asymmetrical band with clear maximum at $438 \mathrm{~nm}$, corresponding to $2.83 \mathrm{eV}$, is usually associated to interstitial zinc atoms ${ }^{25}$. The broad band centered at 560 $\mathrm{nm}(2.21 \mathrm{eV})$, for films annealed at 400 and $800^{\circ} \mathrm{C}$, might be assigned to oxygen vacancies in undoped $\mathrm{ZnO}^{26,27}$. Thus, the intensity of this band suggests that films annealed at 400 


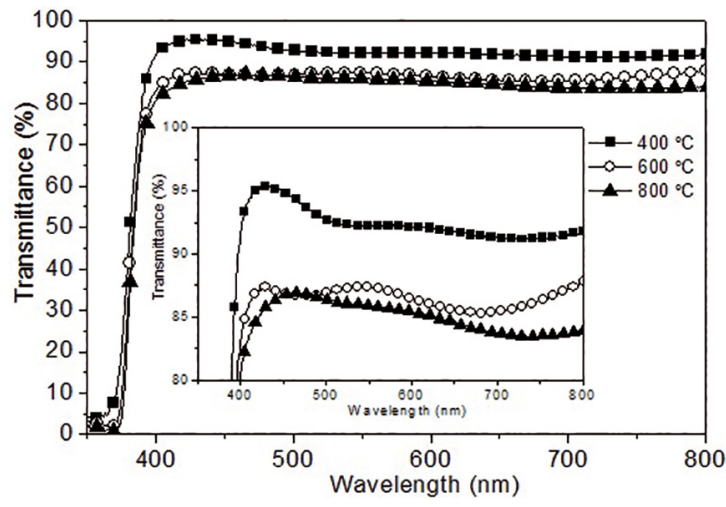

Figure 5: UV-vis transmittance spectra for $\mathrm{ZnO}$ films prepared with isopropanol as a function of annealing temperature.

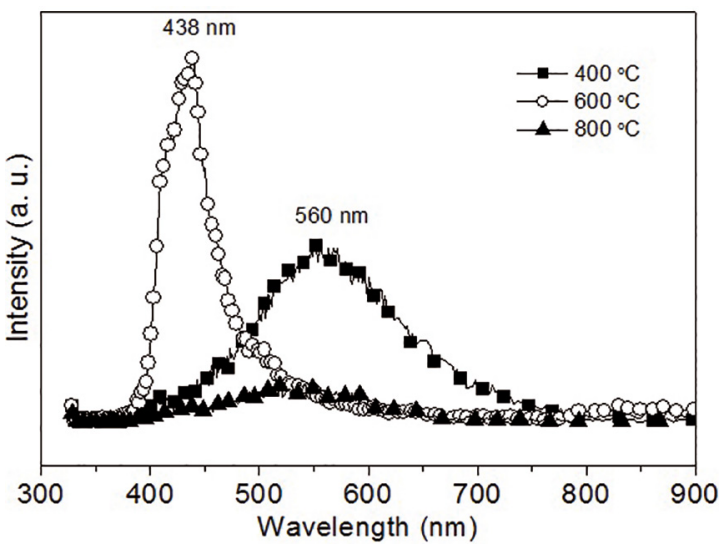

Figure 6: Photoluminescence spectra of $\mathrm{ZnO}$ films prepared at $\mathrm{T}_{\text {anneal }}=400,600$ and $800{ }^{\circ} \mathrm{C}$.

${ }^{\circ} \mathrm{C}$ may have higher amount of oxygen vacancies compared with the other films. Below $400 \mathrm{~nm}(375 \mathrm{~nm}, 3.30 \mathrm{eV})$, no evidence of the near-band-emission (NBE) was observed ${ }^{28}$.

Electrical resistivity of $\mathrm{ZnO}$ films prepared with isopropanol as a function of annealing temperature is shown in Figure 7. The electrical resistivity was found to increase from 7.1 to $1641.7 \Omega \cdot \mathrm{cm}$ for $\mathrm{T}_{\text {anneal }}=400-800^{\circ} \mathrm{C}$. Previous studies have reported electrical resistivity for $\mathrm{ZnO}$ films in the range of 0.1 to $100 \Omega \cdot \mathrm{cm}^{15,29}$. The appropriate annealing temperature to achieve the smallest resistivity was $400{ }^{\circ} \mathrm{C}$, which may have relationship with a high amount of oxygen vacancies. Thus, the favorable oriented growth along (002) plane of $\mathrm{ZnO}$ films prepared at $\mathrm{T}_{\text {anneal }}=600{ }^{\circ} \mathrm{C}$ is not related with low resistivity as suggested in the literature ${ }^{15,19,29}$. The film porosity might adversely influence the light and conductivity phenomena to hinder the positive effect of (002) preferential orientation in $\mathrm{ZnO}$ films. Here, the $\mathrm{ZnO}$ films with relatively smooth surface morphology and less degree (002) orientation, prepared at $\mathrm{T}_{\text {anneal }}=400^{\circ} \mathrm{C}$, show the most attractive optical and electrical properties.

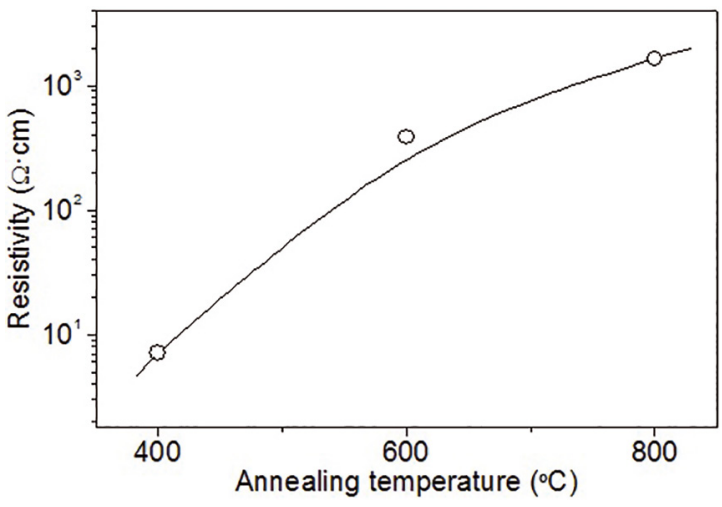

Figure 7: Electrical resistivity of $\mathrm{ZnO}$ films prepared with isopropanol as a function of annealing temperature.

\section{Conclusions}

Highly transparent and (002)-oriented hexagonal wurtzite-type $\mathrm{ZnO}$ films were prepared on quartz substrates by sol-gel spin-coating using isopropanol solvent and zinc acetate precursor. In particular, $\mathrm{ZnO}$ films prepared at $\mathrm{T}_{\text {anneal }}$ $=600{ }^{\circ} \mathrm{C}$ showed the highest (002) preferential orientation, however it was not the significant feature to achieve low resistivity. The uniform and (002)-oriented $\mathrm{ZnO}$ films prepared at $\mathrm{T}_{\text {anneal }}=400{ }^{\circ} \mathrm{C}$ display the highest transmittance $(>93 \%$ in the visible region) and the lowest resistivity $(7.1 \Omega \cdot \mathrm{cm})$.

\section{Acknowledgements}

This study was partially supported by IPN through the project SIP-20161803. One of the authors G.A. VelázquezNevárez gratefully acknowledges the scholarship from CONACYT for doctoral studies.

\section{References}

1. Xu WZ, Ye ZZ, Zeng YJ, Zhu LP, Zhao BH, Jiang L, et al. $\mathrm{ZnO}$ light-emitting diode grown by plasma-assisted metal organic chemical vapor deposition. Applied Physics Letters. 2006;88(17):173506.

2. Zheng K, Guo Q, Wang EG. A buffer layer for $\mathrm{ZnO}$ film growth on sapphire. Surface Science. 2008;602(14):2600-2603.

3. Elangonvan E, Ramamurthi K. A study on low cost-high conducting fluorine and antimony-doped tin oxide thin films. Applied Surface Science. 2005;249(1-4):183-196.

4. Musat V, Teixeira B, Fortunato E, Monteiro RCC, Vilarinho P. Al-doped $\mathrm{ZnO}$ thin films by sol-gel method. Surface and Coatings Technology. 2004;180-181:659-662.

5. Chen CY, Retamal JR, Wu IW, Lien DH, Chen MW, Ding Y, et al. Probing surface band bending of surface-engineered metal oxide nanowires. ACS Nano. 2012;6(11):9366-9372. 
6. Kurbanov SS, Jeon HC, Shaymardanov ZS, Rakhimov RY, Kang TW. Photoluminescence from porous textured $\mathrm{ZnO}$ films grown by chemical bath deposition. Journal of Luminescence. 2016;170(Pt 1):168-173.

7. Treharne RE, Durose K. Fluorine doped $\mathrm{ZnO}$ thin films by RF magnetron sputtering. Thin Solid Films. 2011;519(21):7579-7582.

8. Ravichandran K, Rajkumar PV, Sakthivel B, Swaminathan K, Chinnapa L. Role of precursor material and annealing ambience on the physical properties of SILAR deposited $\mathrm{ZnO}$ films. Ceramics International. 2014;40(8, Part A):12375-12382.

9. Muruganantham G, Ravichandran K, Saravanakumar K, Swaminathan K, Begum NJ, Sakthivel B. Effect of solvent volumen on the physical properties of sprayed fluorine-doped zinc oxide thin films. Crystal Research and Technology. 2012;47(4):429-436.

10. Anusha M, Arivuoli D. High intense violet luminescence in fluorine doped zinc oxide (FZO) thin films deposited by aerosol assisted CVD. Journal of Alloys and Compounds. 2013;580:131-136.

11. Tsay CY, Hsu WT. Sol-gel derived undoped and boron-doped $\mathrm{ZnO}$ semiconductor thin films: Preparation and characterization. Ceramics International. 2013;39(7):7425-7432.

12. Mahroug A, Boudjadar S, Hamrit S, Guerbous L. Structural, optical and photocurrent properties of undoped and Al-doped $\mathrm{ZnO}$ thin films deposited by sol-gel spin coating technique. Materials Letters. 2014;134:248-251.

13. Jensen JM, Oelkers AB, Toivola R, Johnson DC. X-ray reflectivity characterization of $\mathrm{ZnO} / \mathrm{Al}_{2} \mathrm{O}_{3}$ multilayers prepared by atomic layer deposition. Chemistry of Materials. 2002;14(5):2276-2282.

14. Ku CS, Lee HY, Huang JM, Lin CM. Epitaxial growth of ZnO films at extremely low temperature by atomic layer deposition with interrupted flow. Materials Chemistry and Physics. 2010;120(2-3):236-239.

15. Sahal M, Hartiti B, Ridah A, Mollar M, Marí B. Structural, electrical and optical properties of $\mathrm{ZnO}$ thin films deposited by sol-gel method. Microelectronics Journal. 2008;39(12):1425-1428.

16. Basak D, Amin G, Mallik B, Paul GK, Sen SK. Photoconductive UV detectors on sol-gel-synthesized $\mathrm{ZnO}$ films. Journal of Crystal Growth. 2003;256(2-1):73-77.

17. Sharma R, Sehrawat K, Mehra RM. Epitaxial growth of highly transparent and conducting Sc-doped $\mathrm{ZnO}$ films on c-plane sapphire by sol-gel process without buffer. Current Applied Physics. 2010;10(1):164-170.

18. Fujihara S, Sasaki C, Kimura T. Crystallization behavior and origin of c-axis orientation in sol-gel-derived $\mathrm{ZnO}: \mathrm{Li}$ thin films on glass substrates. Applied Surface Science. 2001;180(3-4):341-350.
19. Lee JH, Ko KH, Park BO. Electrical and optical properties of $\mathrm{ZnO}$ transparent conducting films by the sol-gel method. Journal of Crystal Growth. 2003;247(1-2):119-125.

20. Al-Hardan NH, Jalar A, Abdul Hamind MA, Keng LK, Shamsudin R, Majlis BY. The room-temperature sensing performance of $\mathrm{ZnO}$ nanorods for 2-methoxyethanol solvent Sensors and Actuators B: Chemical. 2014;203:223-228.

21. Makiya A, Kusumi Y, Tanaka S, Kato Z, Uchida N, Uematsu $\mathrm{K}$, et al. Grain oriented titania ceramics made in high magnetic field. Journal of the European Ceramic Society. 2007;27(2-3):797-799.

22. Yilmaz M, Caldiran Z, Deniz AR, Aydogan S, Gunturkun R, Turut A. Preparation and characterization of sol-gel-derived $\mathrm{n}-\mathrm{ZnO}$ thin film for Schottky diode application. Applied Physics A. 2015;119(2):547-552.

23. Chen J, Chen D, He J, Zhang S, Chen Z. The microstructure, optical, and electrical properties of sol-gel-derived Sc-doped and Al-Sc co-doped ZnO thin films. Applied Surface Sciences. 2009;255(23):9413-9419.

24. Yoon H, Choi H, Leem JY, Lee SH, Kim JS, Kim JS, Son JS. Optimizing the optical properties of fluorine-doped $\mathrm{ZnO}$ thin films deposited by sol-gel spin-coating. Journal of the Korean Physical Society. 2014;65(4):509-514.

25. Marimuthu T, Anandhan N, Mahalingam T, Thangamuthu R, Mummoorthi M. Effect of P. Murex on the properties of spin coated $\mathrm{ZnO}$ thin films for dye sensitized solar cell applications. Journal of Materials Science: Materials in Electronics. 2015;26(10):7577-7587.

26. Bagnall DM, Chen YF, Shen MY, Zhu Z, Goto T, Yao T. Room temperature excitonic stimulated emission from zinc oxide epilayers grown plasma-assisted MBE. Journal of Crystal Growth. 1998;184-185:605-609.

27. Allabergenov B, Tursunkulov O, Abidov AI, Choi B, Wook JS, Kim S. Microstructural analysis and optical characteristics of $\mathrm{Cu}$-doped $\mathrm{ZnO}$ thin films prepared by $\mathrm{DC}$ magnetron sputtering. Journal of Crystal Growth. 2014;401:573-576.

28. Wang L, Giles NC. Temperature dependence of the freeexciton transition energy in zinc oxide by photoluminescence excitation spectroscopy. Journal of Applied Physics. 2003;94(2):973.

29. Liu Y, Li Y, Zeng H. ZnO-Based Transparent Conductive Thin Films: Doping, Performance, and Processing. Journal of Nanomaterials. 2013;2013(10):1-9. 